\title{
DOCUMENTO
}

\section{REGULAMENTO DAS ESCOLAS MUNICIPAIS DO MUNICÍPIO DE BAGÉ/RS (1925) \\ DOI: http://dx.doi.org/10.1590/2236-3459/58419}

\section{REGULATION OF THE MUNICIPAL SCHOOLS IN THE CITY OF BAGÉ/RS (1925)}

\author{
Alessandro Carvalho Bica \\ Universidade Federal do Pampa, Brasil.
}

\section{Berenice Corsetti}

Universidade do Vale do Rio dos Sinos, Brasil.

\section{$\cos 80$}

projeto republicano de educação na Primeira República, no Estado do Rio Grande do Sul, ancorava-se na expansão do ensino, na extinção do analfabetismo, na modificação dos programas curriculares, na organização e no planejamento do ensino, bem como na aplicação de recursos financeiros à educação. Segunda Corsetti, "a importância da educação primária pública foi posta com insistência, sendo ela ingrediente fundamental do projeto de modernização implementado pelos positivistas no Estado" (1998, p. 171).

O Ato n. 295, de 8 de maio de 1925, estabeleceu o Regulamento das Escolas Municipais, que teve por objetivo unificar e controlar a educação primária pública no município de Bagé. O controle permanente da educação pública foi uma ferramenta defendida pelos republicanos, associada à unidade pedagógica e ao planejamento do ensino (Bica, 2014). 
Sendo assim, o estabelecimento e as imposições contidas no Regulamento das Escolas Municipais, editado pela Intendência Municipal de Bagé no ano de 1925, promoveram as primeiras reformas educacionais na cidade e caracterizaram o primeiro sistema de educação municipal. Neste sentido, podemos pensar que no governo de Carlos Cavalcanti Mangabeira organizou-se, em Bagé, a ideia do município pedagógico ${ }^{1}$.

As ações administrativas e os discursos educacionais foram um elemento propulsor para o avanço econômico, científico e político da sociedade bajeense, bem como vincularam o espaço da escola pública como um elemento essencial para a difusão dos ideais cívicos, morais e republicanos.

Os discursos para a instrução primária pública vincularam os ideais do positivismo aos preceitos republicanos da educação pública, demonstrando que o ensino era o caminho mais viável e rápido no processo de civilizar o povo e de modernizar a nação.

Enfim, a maior herança educacional de Carlos Cavalcanti Mangabeira como intendente municipal de Bagé, entre os anos de 1925 a 1929, foi o estabelecimento do processo da expansão da educação propagado pelo primeiro sistema educacional de ensino do município.

Afinal, a educação foi a melhor forma ou caminho encontrado pelos positivistas para preconizar os símbolos, as crenças, os rituais e os valores da República. Além disso, foi, especialmente a partir do governo de Carlos Cavalcanti Mangabeira, que se manifestaram todas estas possibilidades na campanha gaúcha.

\section{Referências}

BICA, Alessandro Carvalho. A organização da educação pública municipal no governo de Carlos Cavalcanti Mangabeira (1925-1929) no município de Bagé/RS. Tese (doutorado em Educação). Universidade do Vale do Rio dos Sinos.

CORSETTI, Berenice. Controle e ufanismo: a escola pública no Rio Grande do Sul (18901930). Santa Maria: UFSM, 1998. 538f. Tese (doutorado em Educação). Universidade Federal de Santa Maria, Centro de Educação.

ALESSANDRO CARVALHO BICA é professor adjunto na Universidade Federal do Pampa, campus de Bagé e líder do Grupo de Estudos em Educação, História e Narrativas.

Endereço: Rua Ari Silveira Azambuja, 450 - 96412-835 - Bagé - RS - Brasil.

E-mail: alessandro.bica@unipampa.edu.br.

\footnotetext{
${ }^{1}$ Sobre a ideia de município pedagógico na história da educação brasileira consultar: CARVALHO, Carlos Henrique de. O município pedagógico e a descentralização do ensino no Brasil: a educação em Minas Gerais no início da República (1889-1906). Revista Ibero-Americana de Estudos em Educação, Araraquara (Unesp), v. 5, n. 2, 2010, p. 1-17. GONÇALVES NETO, Wenceslau. Organização do ensino público no final do século XIX: o processo legislativo em Uberabinha, MG. Cadernos de História da Educação. Uberlândia: UFU, n. 2, 2004, p. 59-62; GONÇALVES NETO, Wenceslau. História e memória da educação: a organização do sistema escolar em Uberabinha, MG, no final do século XIX. Hist. Educ. (Online). Porto Alegre: Asphe, v. 9, n. 17, 2005, p.137-156. 
BERENICE CORSETTI é professora titular na Universidade do Vale do Rio dos Sinos. Endereço: Avenida Unisinos, 950 - 93022-000 - São Leopoldo - RS - Brasil. E-mail: bcorsetti@unisinos.br.

Recebido em 10 de setembro de 2015.

Aceito em 23 de novembro de 2015. 
INTENDENCIA MUNICIPAL DE BAGÉ

\title{
REGULAMENTO \\ DAS \\ ESCOLAS MUNICIPAIS
}

\author{
1925 \\ Typographia da "Casa Maciel" \\ Bagé
}

ACTO N. 295

Approva o regulamento das escolas municipais.

O intendente municipal de Bagé, no uso de suas attribuições legais, approva o regulamento das escolas municipais, que com este baixa.

Intendencia municipal de Bagé, 8 de maio de 1925.

Carlos Cavalcante Mangabeira.

Intendente.

\section{Capitulo I}

\section{Da creação e do funccionamento das escolas}

Art. $1^{\circ}$ - Serão creadas tantas escolas quanto forem necessarias para diffusão do ensino no municipio.

Art. $2^{\circ}$ - Nos districtos rurais, no lugar que fôr verificada a existencia de uma população escolar de cincoenta crianças, em condições de receber ensino, será installada uma escola.

Para esse fim, o sub intendente do districto ou os moradores do lugar, solicitarão ao intendente, justificadamente, a necessidade de creação da escola.

Art. $3^{\circ}$ - As escolas que tiverem uma frequencia inferior a quinze alumnos, serão fechadas, e o professor removido para outro lugar, onde seja maior a população escolar.

Art. $4^{\circ}$ - As escolas funccionarão em casas de aluguel, arrendadas ou offerecidas pelos proprietarios, dotando-as a municipalidade de todas as condições hygienicas, até que sejam construidos edificios proprios. $\mathrm{O}$ mobiliario e o material necessarios para $\mathrm{o}$ ensino, serão fornecidos pela intendencia.

Art. $5^{\circ}$ - As escolas mixtas, o ensino leigo e gratuito, obedecendo ao programma organizado pela commisão de que trata o art. $10^{\circ}$ deste regulamento. 
Art. $6^{\circ}$ - É livre a matricula ás crianças de qualquer sexo, raça ou nacionalidade, de 7 a 14 annos de idade. Não terão ingresso nas escolas mixtas, alumnos do sexo masculino, maiores de 14 anos.

$\S$ único - A matricula será feita verbalmente ao professor, pelos pais ou tutores dos candidatos ou por estes. Não serão matriculados os candidatos que soffrerem molestias contagiosas.

Art. $7^{\circ}$ - O anno lectivo terá inicio no primeiro dia util de do mês de Março e será encerrado depois dos exames, que serão feitos na segunda quinzena do mês de Dezembro, em dia que for determinado, perante uma commisão composta de tres membros, nomeada pelo intendente e presidida pelo inspector.

Art. $8^{\circ}$ - O horario das escolas será das 9 ás 11 e das 13 ás 16 horas.

Art. $9^{\circ}$ - Em cada escola haverá tres livros, sendo um para a matricula dos alumnos, um para as actas de exame e um para a carga do material existente.

\section{Capitulo II \\ Do programma de ensino}

Art. $10^{\circ}$ - O programma de ensino será organizado pelo inspector e por uma commisão de professores do collegio elementar, convidada pelo intendente.

$\S 1^{\circ}$ - O programma será revisto annualmente, fazendo se ou não as alterações que forem julgadas necessarias.

$\S 2^{\circ}$ - Os livros serão os adoptados pela instrucção publica do Estado.

\section{Capitulo III \\ Dos professores e seus deveres}

Art. $11^{\circ}$ - Os professores são de livre nomeação do intendente.

Art. $12^{\circ}$ - São exigidas as condições seguintes para ser professor:

a) Ser brasileiro nato ou naturalizado, maior que 21 e menor que 55 annos;

b) Provar que nada tem que o desabone;

c) Ter a necessaria habilitação, julgada por uma commisão examinadora, escolhida pelo intendente e presidida pelo inspector, no exame a que será submetido.

Art. $13^{\circ}$ - Todos os professores teem por dever:

a) Manter sem interrupção o funccionamento das escolas durante o periodo lectivo, só o fazendo por força maior ou com permisão do intendente;

b) Cumprir, rigorosamente, o programma de ensino;

c) Fazer sentir aos chefes de familia, em palestra ou por qualquer outro meio de propaganda, o mal do analphabetismo, incutindo-Ihes no espirito a necessidade de mandarem seus filhos á escola;

d) Providenciar para que seja içada a bandeira nacional nos dias de feriados pela Republica e pelo Estado, encarregando dessa missão o alumno mais applicado;

e) Reunir nesses dias todos os alumnos e fazer preleção sobre a data que se commemora e chamar-Ihes a attenção para as vantagens do ensino;

f) Ser delicado e bom para os alumnos, tratando os com o maior carinho e fazendoIhes comprehender que seu educador é um amifo e protector; 
g) Não applicar castigdo corporaes, nas faltas que forem commetidas, impondo, sómente, penas de tarefas escriptas, que redundem em proveito dos alumnos;

h) Apresentar todos os meses mappa da matricula e frequencia dos alumnos, afim de receberem seus vencimentos no thesouro municipal.

\section{Capitulo IV \\ Da inpectoria}

Arft. 14 - As escolas municipais terão um inspector, que reunirá todas as qualidades indispensaveis para essa elevada missão.

Art. $15^{\circ}$ - Soa deveres do inspector:

a) Inspeccionar todas as vezes que entender e de surpresa, as escolas municipais;

b) Apresentar ao intendente um relatorio minucioso de tudo que observar nas escolas, propondo as medidas que julgar convenientes para o seu funccionamento;

c) Presidir aos exames no fim do anno lectivo;

d) Rubricar, mensalmente, os mappas que os professores apresentarem da matricula e frequencia de alumnos, afim de receberem seus vencimentos no thesouro municipal;

e) Propor ao intendente a remoção dos professores, a suppresão provisoria ou definitiva das escolas, que não tiverem a frequencia determinada por este regulamento;

f) Suspender os professores que não corresponderem ás funcções de seu cargo, levando este facto ao conhecimento do intendente;

g) Tomar todas as medidas que julgar convenientes ao interesse do ensino, communicando-as previamente ao intendente.

\section{Capitulo V \\ Da fiscalização das escolas}

Art. $16^{\circ}$ - As escolas nos districtos rurais serão fiscalizadas pelos respectivos subintendentes, a quem compete:

a) Visitar, seguindamente, as escolas, tomando conhecimento da frequencia dos alumnos, assiduidade e procedimento dos professores, asseio e hygiene das aulas;

b) Levar ao conhecimento do intendente e inspector tudo que observar nas escolas;

c) Visar os mappas de matricula, procurando saber com segurança se elles exprimem a verdade;

\section{Capitulo VI \\ Dos vencimentos do inspector e professores}

Art. $17^{\circ}$ - são fixados, mensalmente, os vencimentos do inspector, em 200\$000; dos professores que leccionarem de 15 a 25 alumnos, em 150\$000; dos que leccionarem de 26 a 40 alumnos em $200 \$ 000$.

$\S$ único - o inspector terá maus uma diaria, arbitrada pelo intendente, quando no interior do municipio, em serviço de seu cargo. 
Art. $18^{\circ}$ - Os vencimentos serão divididos em tres partes, sendo dois terços a titulo de ordenado e um terço como gratificação de exercicio.

Art. $19^{\circ}$ - Será concedida uma gratificação especial, no fim do anno lectivo, aos professores que provarem, mediante attestado do inspector, do sub-intendente, dos pais dos alumnos ou de outras pessoas gradas, os seus esforços pelo ensino e pelo maior numero de educandos, a qual será fixada pelo intendente.

\section{Capitulo VII Disposições finais}

Art. $20^{\circ}$ - Fica isento de imposto municipais, o chefe de familia que tiver tres filhos frequentando, com assuduidade, as aulas, de accordo com a autorização que oportunammente será solicitada ao Conselho.

Art. $21^{\circ}$ - Serão concedidos premios, pelo intendente ou por outras pessoas que visarem o mesmo objectivo, aos alumnos que demonstrarem melhor aproveitamento nos exames finais.

Art. $22^{\circ}$ - O municipio fornecerá ás crianças reconhecidamente pobres, o material que fôr necessario para seu ensino.

Art. $23^{\circ}$ - Serão conservadas as escolas suburbanas e extinctas, gradativamente, as da cidade onde existem estabelecimentos de ensino, mantidos pelo governo do Estado.

Art. $24^{\circ}$ - Ficam asseguradods os direitos dos actuais professores, desde que se sujeitem ás disposições do presente regulamento, a vigorar da data de sua publicação.

Art. $25^{\circ}$ - A municipalidade subvencionará qualquer escola que ministre ensino gratuito, justificados a frequencia e o aproveitamento dos alumnos.

Art. $26^{\circ}$ - Na sede do municipio, reconhecida a necessidade, serão creados grupos escolares dirigidos por tres professores. As suas aulas funccionarão pela manhã, á tarde e á noite.

Art. $27^{\circ}$ - Das penas que Ihes forem impostas, pelo inspector, poderão os professores recorrer para o intendente, que decidirá de accordo com as razões apresentadas.

Art. $28^{\circ}$ - Será resolvido pelo intendente o que não estiver previsto neste regulamento.

Art. $29^{\circ}$ - Revogam-se as disposições em contrario.

Secretaria do Municipio de Bagé, 8 de maio de 1925.

Carlos Cavalcante Mangabeira.

Intendente.

Pedro A. Cunha.

Secretario. 